\title{
Effect of adding additional Carbon Fiber on Piezoresistive Properties of Fiber Reinforced Concrete Pavements under Impact Load
}

\author{
Ayad K. Mohammed $^{\mathrm{a}^{*}}$, Ali M. Al-Dahawi ${ }^{\mathrm{b}}$, Qais S. Banyhussan ${ }^{\mathrm{c}}$ \\ a,b Civil Engineering Dept., University of Technology-Iraq, Alsina'a street,10066 Baghdad, Iraq. \\ ${ }^{\mathrm{c}}$ Highways and Transportation Engineering Dept., Mustansiriayah University, Baghdad, Iraq. \\ *Corresponding author Email: 42371@,student.uotechnology.edu.iq
}

\section{H I G H L I G H T S}

- Self-sensing and mechanical behavior of FRCP under impact loads were assessed.

- Carbon fibers and steel fibers were utilized to improve the mechanical and piezoresistive properties.

- The best impact energy results were achieved when only 0.5 and $1.0 \%$ vol. $\%$ of $\mathrm{CF}$ and SF respectively.

- Successful self-sensing of damage was obtained with superior performance of CF.

\section{A R T I C L E I N F O}

Handling editor: Wasan I. Khalil

Keywords:

Multifunctional cementitious composite

Self-sensing

Hybrid fiber

Electrically conductive material

Piezoresistivity capacities

\begin{abstract}
A B S T R A C T
Multifunctional Cementitious Composite (MCC) characteristics are directly related to the type and dosage of the Electrically Conductive Materials (ECMs) reinforcing the relevant concrete matrices. This study investigated the electromechanical capacities of fiber reinforced concrete pavement (FRCP) with and without the addition of micro scale-carbon fiber (CF). The impact energy of FRCP under compacted load was evaluated initially; then, the effects of $0.5 \%$ and $1 \%$ content by volume of CF on the piezoresistivity capacities of FRCP were investigated under applied impact load. This type of load is the most common force causing long-term rigid pavement deterioration. Obtained results showed that the use of a hybrid fiber (micro-scale carbon fiber $0.5 \%$ and macro-scale steel fiber $1 \%$ by volume) enhanced the impact strength (impact energy) due to CF's resistance to micro-cracks. The developed FRCP showed good results in terms of self-sensing under compact load with both 0.5 and $1.0 \%$ by volume of CF.
\end{abstract}

\section{Introduction}

Many constructional structures are likely to be exposed to impact forces over time. Impact forces may be of many shapes and for various reasons. One example is the accident effect of transport vehicle's bays, roads, and building walls [1].

In recent decades, the interest in the use of steel and synthetic fibers for concrete mixtures is growing. One of the main features of Fiber Reinforced Concrete (FRC) is impact strength enhancement. High strength to impact means both higher energy and higher intensity absorption of impacts. For civil and military structural applications, FRC was notably used in recent years. Channel lining, bridge decking, industrial flooring, airport pavements, are examples of those applications, Infrastructure offshore and military $[2,3]$. Several test methods were suggested by similar researchers and standards to achieve an acceptable FRC impact resistance measurement. The parameters studied depend on each form of these tests, and the mechanism for applying the impact load is widely varied. The Charpy pendulum, drop weight, projectile effect, explosive, and repeated drop weight are among these measures of effect research (RBDWI) $[4,5]$.

Structural Health Monitoring (SHM) is used for the monitoring and inspection of structural efficiency of buildings and public facilities during their ongoing operation [6, 7]. Commonly, SHM approaches have used embedded or structural sensors; however, such sensors are expensive, with low sensitivity and poor durability [8-15]. In this study, two types of conductive materials were used to make concrete pavement capable of sensing loads and damage in the form of cracking by detecting electrical resistivity. Self-sensing materials, sometimes called multifunctional or smart materials [16] come in various forms, with additions including carbon fiber, steel fiber, carbon nanotubes (CNTs), carbon black, nickel powder, graphite powder, and 
steel slag having been used to increase electrical conductivity and piezoelectricity in cement-based construction materials [915, 17-22]. Among these smart fillers, carbonic materials have been reported as exhibiting excellent detection capabilities in cement-based composites as well as in epoxy or polymer composites [7, 23-26].

Smart materials with self-sensing capabilities that use CF and/or CNTs have improved significantly their piezoresistive capabilities; however, their sensing ability is still limited to the linear elastic range [27-31]. On the other hand, macro steelreinforced cementitious composites under direct tension have recently been shown to have electro-mechanical damage sensing capabilities even after the first cracking $[32,33]$. Typical sensing behavior of self-sensing concrete under tension includes increased electrical resistance (ER) after the first crack [34]. Reinforced concrete with macro steel fibers showed significant decreases in electrical resistivity during the direct tension strain-hardening process from first cracking to post cracking [35]. Banthia et al. [36] investigated the electrical resistivity of cement paste with micro steel and carbon fibers, recording a significant reduction in the resistivity of matrices reinforced with both micro-scale fibers and CF; the latter improved the conductivity of the paste better than the inclusion of steel fiber, however, conflicting with Wen and Chung [37]. Macro-steel fiber reinforced concrete with the correct type and content of fiber also improves the mechanical properties of matrices concerning stress-hardening performance [38-44], emphasizing the importance of increasing the FRCP material's self-sensing ability without reducing the mechanical properties of the matrix to be used in SHM applications.

In the present study, hybrid fiber (micro-scale carbon fiber (CF) and macro end hook steel fiber (S)) are investigated for this purpose. The main objectives of the study were thus to evaluate the effects of different fibers utilization on the impact energy and the effects of CF content on the self-sensing capabilities of FRCP under impact load.

\section{Experimental framework}

The steps of the experimental program to explore FRCP, impact energy and piezoresistive properties were planned, as illustrated in Figure 1. All mixtures were allotted the same concrete matrix with the addition of different smart materials. To achieve the first purpose of the study, the additives were as follows: (a) $1.0 \%$ by vol. macro end hook steel fibers (S), (b) $0.5 \%$ by vol. microscale $\mathrm{CF}$, (c) $0.5 \%$ by vol. microscale $\mathrm{CF}$ and $1.0 \%$ by vol. macro end hook steel fibers (S), (d) $1.0 \%$ by vol. microscale $\mathrm{CF}$ and $1.0 \%$ by vol. macro end hook steel fibers (S). The second objective of the study was achieved by testing the specimens prepared with FRCP containing $1.0 \%$ by volume of macro end hook steel fibers, CF0S1, then adding micro-scale carbon fibers $(\mathrm{CF})$ by volume to the CFOS1. These percentage additions varied from $0 \%$ to $1 \%$, with a $0.5 \%$ step change, giving $0 \%$ vol. (CF0S1), $0.5 \%$ vol. (CF0.5S1), and $1.0 \%$ vol. (CF1S1).

\subsection{Materials and Mix proportions}

The constituent materials used to produce the conductive FRCP were Type 1 Ordinary Portland cement manufactured in Iraq with the commercial name of Tasluga, Bazian, which was compliant with the Iraqi Specifications No. 5, 1984 [45]; fly ash (Class-F), per ASTM-C618 (2005) [46]; and silica fume according to requirements of ASTM-C1240 [47], to enhance the distribution of smart materials. Table 1 lists the chemical compositions of the various materials. Crushed gravel of $19 \mathrm{~mm}$ maximum size and fine Zone III aggregate, compliant with the Iraqi Specifications No. 45, 1984 [48] was adopted. A high range water reducer (HRWR) based on modified polycarboxylate-ether, Sika 5930-L, was used as a superplasticizer to mobilize the workability characteristics of FRCP. In terms of the smart materials, or electrically conductive materials (ECMs), microscale carbon fibers of $12 \mathrm{~mm}$ length (CF12) were used in two different percentages in the FRCP mixes and macro end hook steel fibers (S) with lengths of $30 \mathrm{~mm}$ and $50 \mathrm{~mm}$ were used, as shown in Figure 2. Table 2 lists the physical properties of the FRCP. The mix proportions of the concrete matrix used in this study were the same for all specimens tested, as shown in Table 3. The selected mix proportions were based on previous studies [9, 10, 49-51].

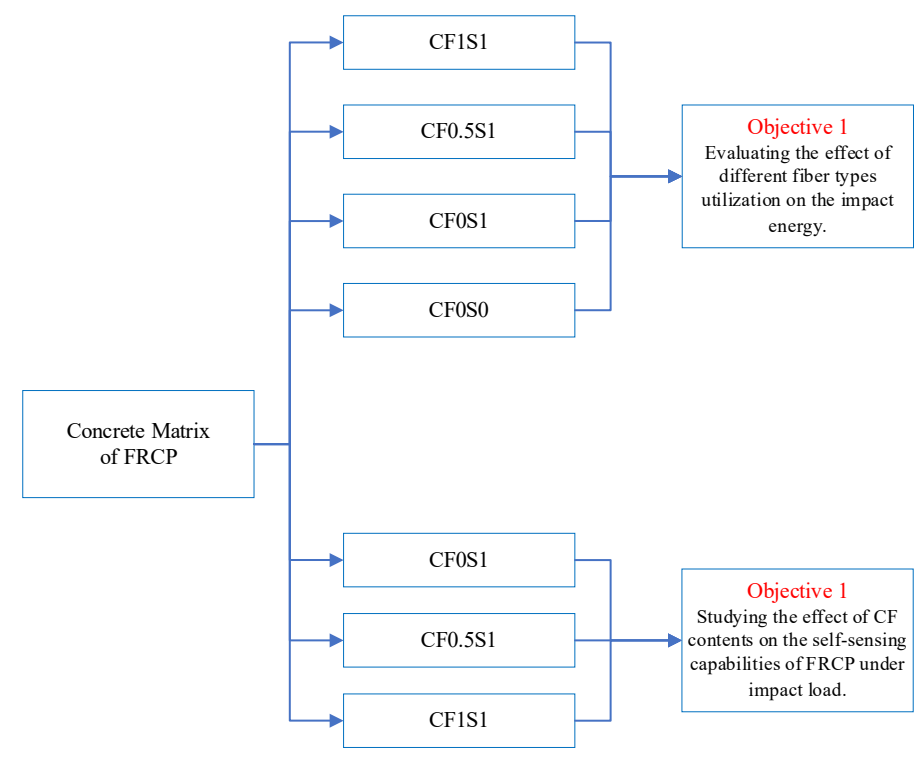

Figure 1: Flow chart of the experimental program 


\subsection{Mixing procedure}

All materials included in the FRCP were mixed in the laboratory with a planetary mixer of $100 \mathrm{~L}$ maximum capacity. The crushed gravel and fine aggregates were mixed in a dry state for three minutes initially; then, the Portland cement (PC), fly ash (FA) and microscale carbon fibers (CF) were added to the dry aggregate blend. Mixing was continued for an additional 10 minutes, then the SF, HRWRA, and water were mixed separately before being added to the previously prepared PC-FA-CFaggregate blend, with mixing continued for a further 5 minutes. Finally, micro end hook steel fibers (S) were added to the fresh concrete mixture, which was mixed for additional 5 minutes to produce a homogenous material.

\subsection{Specimen Preparation}

The concrete mixture was cast into $\phi 150 \times 65 \mathrm{~mm}$ disc molds. Electrodes were inserted at $27.5 \mathrm{~mm}$ inwards from the side surfaces and perpendicular to the pouring face of the disc mold. All samples were subjected to slight vibration using a table vibrator to remove air bubbles before being covered with a plastic sheet and stored at room temperature in the lab for 24 hours as shown in Figure 3. All specimens were cured in a laboratory in a curing tank set at $23 \pm 2{ }^{\circ} \mathrm{C}$. After curing, the specimens were dried for 24 hours at $60{ }^{\circ} \mathrm{C}$ to eliminate any possible effects of internal humidity on electrical measurements due to polarization [22, 52-54]. The specimens were then tested at the ages of 7 and 28 days.

\subsection{Impact test setup for electro-mechanical measurement and procedures}

Impact test was conducted in this research to evaluate the electromechanical performance of the hybrid fiber-reinforced concrete under repeated impact loading (dynamic load) using the repeated blows test that is recommended by ACI544.2R (2017) [5]. The impact strength, which is dependent on the energy absorption capacity (impact energy) of each specimen was calculated using Equation (1) at 7 and 28 days old. Dimensions are shown in Figure 4.

Table 1: Chemical compositions of cementitious materials

\begin{tabular}{llll}
\hline Chemical Composition \% & Cement & Fly Ash & Silica fume \\
\hline $\mathrm{SiO} 2$ & 21.33 & 52.22 & 85.96 \\
$\mathrm{Al} 2 \mathrm{O} 3$ & 3.74 & 16.58 & 1.2 \\
$\mathrm{Fe} 2 \mathrm{O} 3$ & 4.76 & 6.6 & 0.84 \\
$\mathrm{CaO}$ & 62.35 & 7.98 & 0.62 \\
$\mathrm{SO} 3$ & 2.01 & 0.02 & - \\
$\mathrm{MgO}$ & 3.37 & 2.1 & 1.02 \\
\hline
\end{tabular}

Table 2: Physical properties of FRCP

\begin{tabular}{lll}
\hline Material & Properties & \\
\hline \multirow{2}{*}{ Normal Portland Cement } & Specific Gravity & 3.06 \\
Fly ash & Specific surface area $\left(\mathrm{m}^{2} / \mathrm{kg}\right)$ & 394 \\
& Specific Gravity & 2.02 \\
Silica fume & Specific surface area $\left(\mathrm{m}^{2} / \mathrm{kg}\right)$ & 295 \\
& Specific Gravity & 2.4 \\
Crushed gravel & Specific surface area $\left(\mathrm{m}^{2} / \mathrm{kg}\right)$ & 15000 \\
& Specific Gravity & 2.63 \\
Fine Aggregates & Water Absorption $\%$ & 1.167 \\
& Specific Gravity & 2.6 \\
High range water & Gradation & Zone III \\
reducer (HRWR) & Fineness Modulus & 2.5 \\
& Specific Gravity & 1.15 \\
Micro scale Carbon Fiber & Length of Fiber & $12 \mathrm{~mm}$ \\
& Specific Gravity & 1.7 \\
& Carbon Content & $95 \%$ \\
& Tensile Strength MPA & 4150 \\
& Tensile Modulus Gpa & 252 \\
& Filament Diameter $(\mu \mathrm{m})$ & 7 \\
& Length of Fiber & $30 \mathrm{~mm}$ \\
Specific Gravity & 7.8 \\
& Aspect Ratio & 60 \\
& Filament Diameter $(\mathrm{mm})$ & 0.5 \\
& Tensile Strength MPA & 1650 \\
& Length of Fiber & $50 \mathrm{~mm}$ \\
& Aspect Ratio & 71 \\
& Filament Diameter $(\mathrm{mm})$ & 0.7 \\
& Tensile Strength MPA & 1800 \\
\hline
\end{tabular}


Table 3: Mixture proportions for FRCP.

\begin{tabular}{lllllll}
\hline \multicolumn{2}{l}{ Unit Weight } & $\left(\mathbf{k g} / \mathbf{m}^{3}\right)$ & & & & \\
\hline Cement & Fly ash & Silica fume & W/B & SP & Sand & Gravel \\
400 & 180 & 30 & 0.4 & 6.1 & 588 & 788 \\
\hline
\end{tabular}

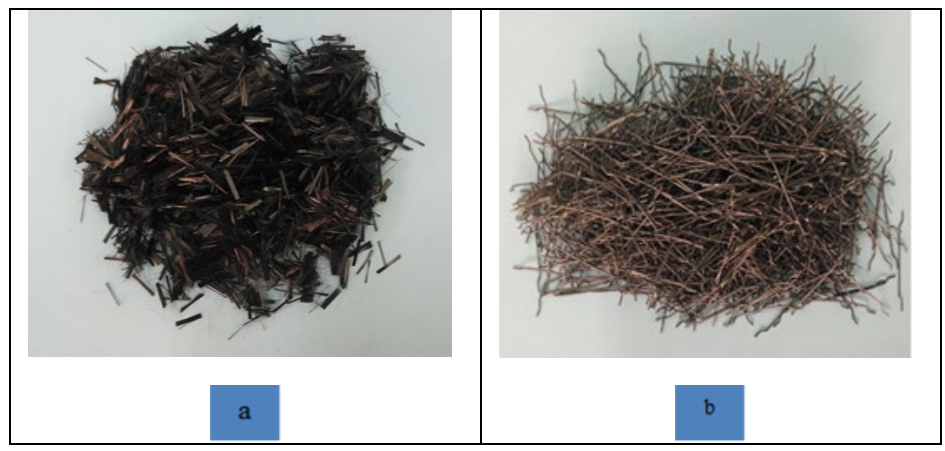

Figure 2: Smart materials added to the concrete matrix: (a) micro-scale carbon fiber with $12 \mathrm{~mm}$ length; (b) macro end hook steel fiber with $30 \mathrm{~mm}$ and $50 \mathrm{~mm}$ lengths.

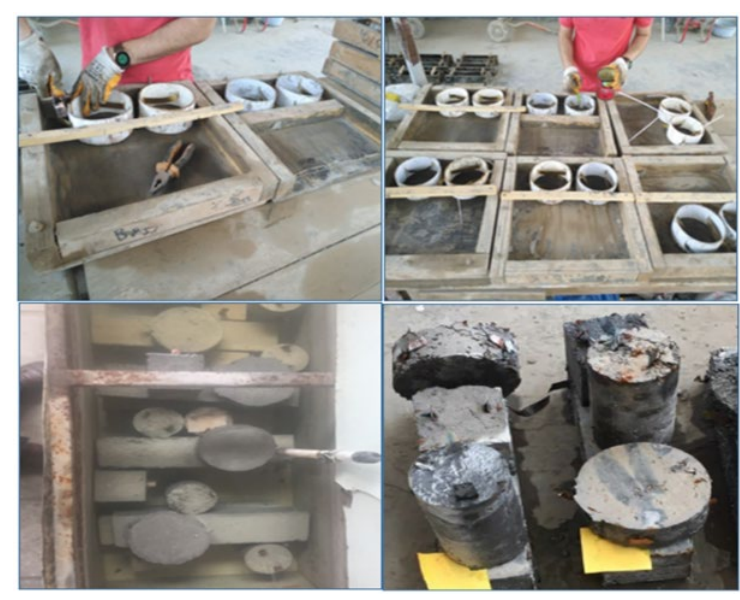

Figure 3: Stages of specimens' preparation

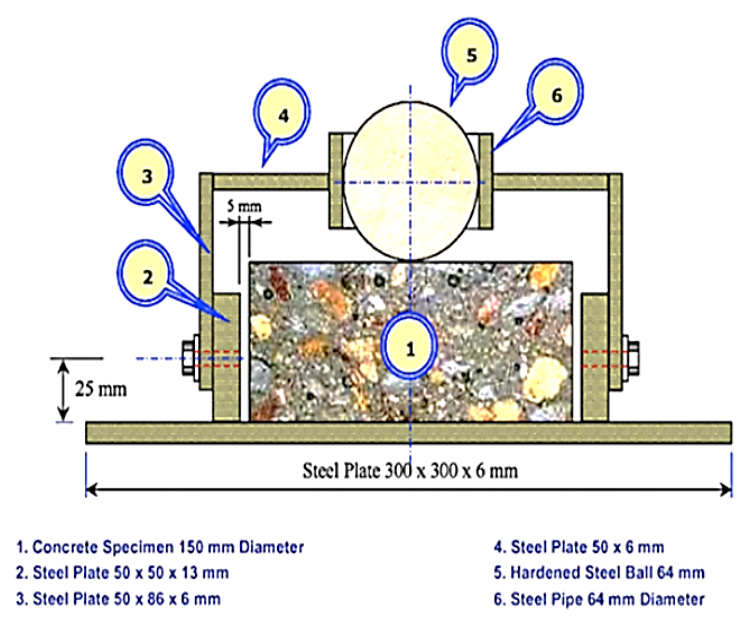

Figure 4: Impact test setup [55]

$\mathrm{E} \operatorname{imp}=\mathrm{m} \times \mathrm{g} \times \mathrm{h} \times \mathrm{n}$

where: Eimp: absorbed energy (J). m: drop mass (4.5) kg. g: gravity acceleration $(9.8) \mathrm{m} / \mathrm{s}^{2} . \mathrm{n}$ : number of impacts. h: falling depth (45) $\mathrm{cm}$.

The system employed in this study to calculate the changes in electrical resistivity with impact load application was based on a two-probe method. Two brass electrodes with a width of $10 \mathrm{~mm}$ were embedded into each specimen when it was in a fresh statement parallel to the applied load. The electrodes were thus perpendicular to the indirect tensile strain. The locations and dimensions of the electrodes are exhibited in Figure 5. To capture the electrical resistivity of the tested specimen, a digital multi-meter was used using the two-probe method under an applied direct current (DC). 
The test procedure, firstly, starts by putting a thin rubber on the steel base plate to electrically isolate the specimen being tested before positioning between the base lugs, and then the specimen is bolted using the positioning brackets. Secondly, a $4.54 \mathrm{~kg}$ drop weight is released from a height of $45 \mathrm{~cm}$ repeatedly by using the electromechanical method that hits a steel ball with a diameter of $64 \mathrm{~mm}$, which would come in contact with the top surface of the concrete specimen. The number of impact blows was recorded automatically by the device and during the test application, the electrical resistance was measured by the digital multimeter. Finally, the test continues until the fracture of the specimen.

The electrical resistance was then translated using Equation (2) into electrical resistivity ( $\rho$ ) of the material; the digital multi-meter data, as based on the theory underlying in Equation (2) was then used to evaluate the piezoresistive behaviour of the FRCP in terms of fractional change in electrical resistivity (FCER) by applying Equation (3) under the impact load. The electrical resistance was captured with the aid of software designed to connect the digital multimeter with the computer, as shown in Figure 6.

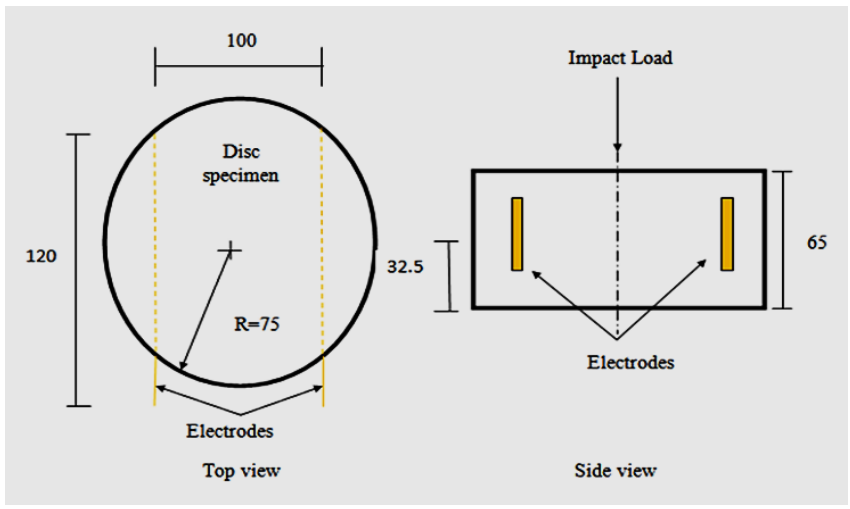

Figure 5: Geometrical details of electrodes (all dimensions are in $\mathrm{mm}$ )

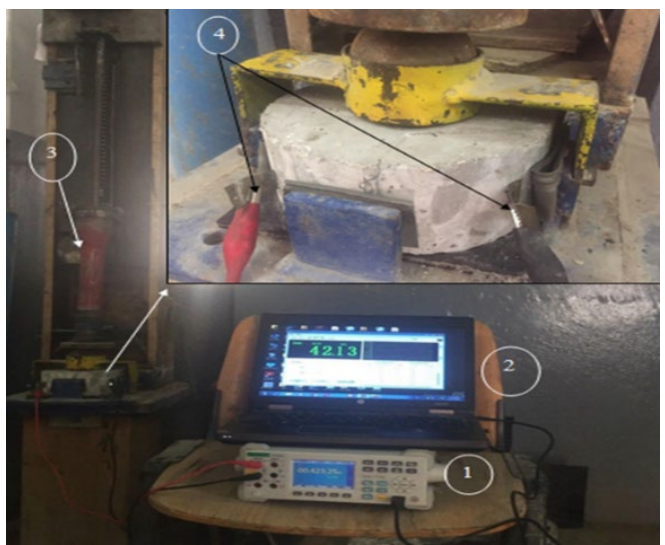

Figure 6: Impact loading setup: (1) a digital multi-meter (2) electrical resistivity software (3) drop hammer with $4.5 \mathrm{~kg}$ weight (4) probes for DC

Electrical Resistivity $(\mathrm{R})=\rho . \mathrm{A} / \mathrm{L}$

Where $\rho$ is the electrical resistance $(\Omega)$; A is the area of cross-section $\left(\mathrm{m}^{2}\right)$, and $\mathrm{L}$ is the space between the two electrodes $(\mathrm{m})$.

Fractional Change in Electrical Resistivity $($ FCER \%) $=\Delta \mathrm{R} / \mathrm{R} \times 100$

Where $\Delta \mathrm{R}$ is the change in electrical resistivity and $\mathrm{R}$ is the preliminary electrical resistivity of the specimen.

\section{Experimental Results and Discussion}

Impact load study was conducted according to ACI committee 544, and mechanical performance was investigated by averaging the number of blows at the final fracture to calculate the absorbed energy. Average absorbed energy results of the mixtures with different curing ages of FRCP were summarized in Table 4. In general, the addition of steel fiber to FRCP improved the impact energy for concrete matrix compared with CF. for instance, for CF0S0-0.4-400 mixture, when $1.0 \%$ by vol. of steel fibers were added into FRCP, this increased the impact energy by $323 \%$ compared with the result of control with CF $0.5 \%$ by vol., which increased the impact energy by only $10.8 \%$ after 7-day of curing, as shown in Figure 7 . Because of their greater length and improved cohesion, macro-end hook steel fibers have a better performance than CF fibers because of their hook end [55]. Whereas adding of CF 0.5 and $1.0 \%$ by vol. into FRCP increasing the impact energy by 10 and 7 times, respectively compared with the control mixture after 7 days of curing. It can be seen in Figure 7 that CF contributes to delaying the development of microcracks at low stress. This can be attributed to the tensile strength compared with steel fibers [37, 56]. When the CF was added beyond $0.5 \%$ vol., it was observed a slight reduction in impact energy, which can be attributed to the increased air voids content in the concrete matrix at a high dosage of CF that led to the weak bond strength of fiber-matrix 
[57]. The impact energy results were gradually improved with long curing ages, as shown in Figure 7 . This is due to the effect of continuous hydration reactions which densify the matrices of concrete [58].

The graphs shown in Figure 7 are based on the results of three-disc specimens for each mixture type and were drawn to monitor the changes in results of FCER with time, after applying impact-loading (falling hammer weight (4.5kg), drop height $(45 \mathrm{~cm})$, falling time each $2 \mathrm{sec}$, continuous until failure). In general, the inclusion of CF into FRCP improves the piezoresistive behaviour under impact test, i.e. improves the stress/strain sensing ability and reversibility with unloading early. These phenomena were stated in previous studies [37, 59]. For CF0S1 mixture, after 7 days of curing, when CF $0.5 \%$ and $1.0 \%$ by vol. were added, the FCER were increased by 7 and 38 times, respectively compared with the results of CF0S1 at the 6th sec, as shown in Figure 8, which can be attributed to the presence of CFs that are considered more conductive than steel fibres. Also, the reversibility was improved upon unloading early (elastic range) [36]. That reversibility in the FCER results with unloading was attributable to the conductive filler separation and decreases that occurred due to the convergence of conductive fillers after the unloading, in addition to the high aspect ratio of these fillers [22]. Figure 9 shows the failure of specimens under impact load.

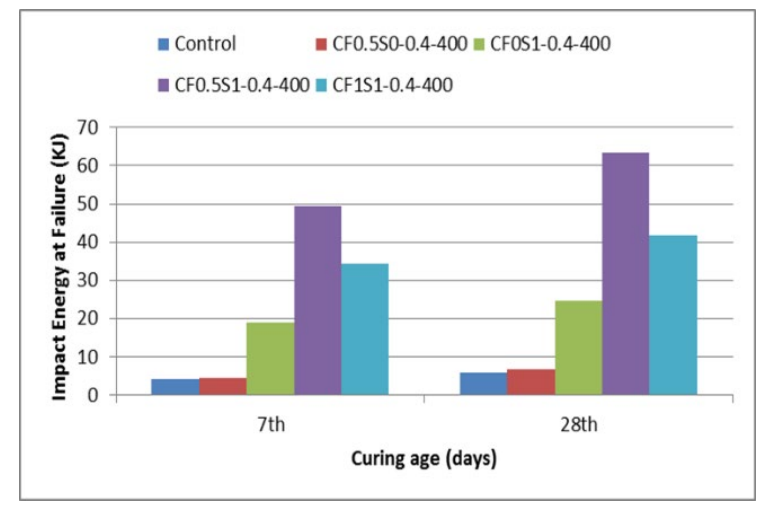

Figure 7: Effect of different fibers utilization on the average impact energy results
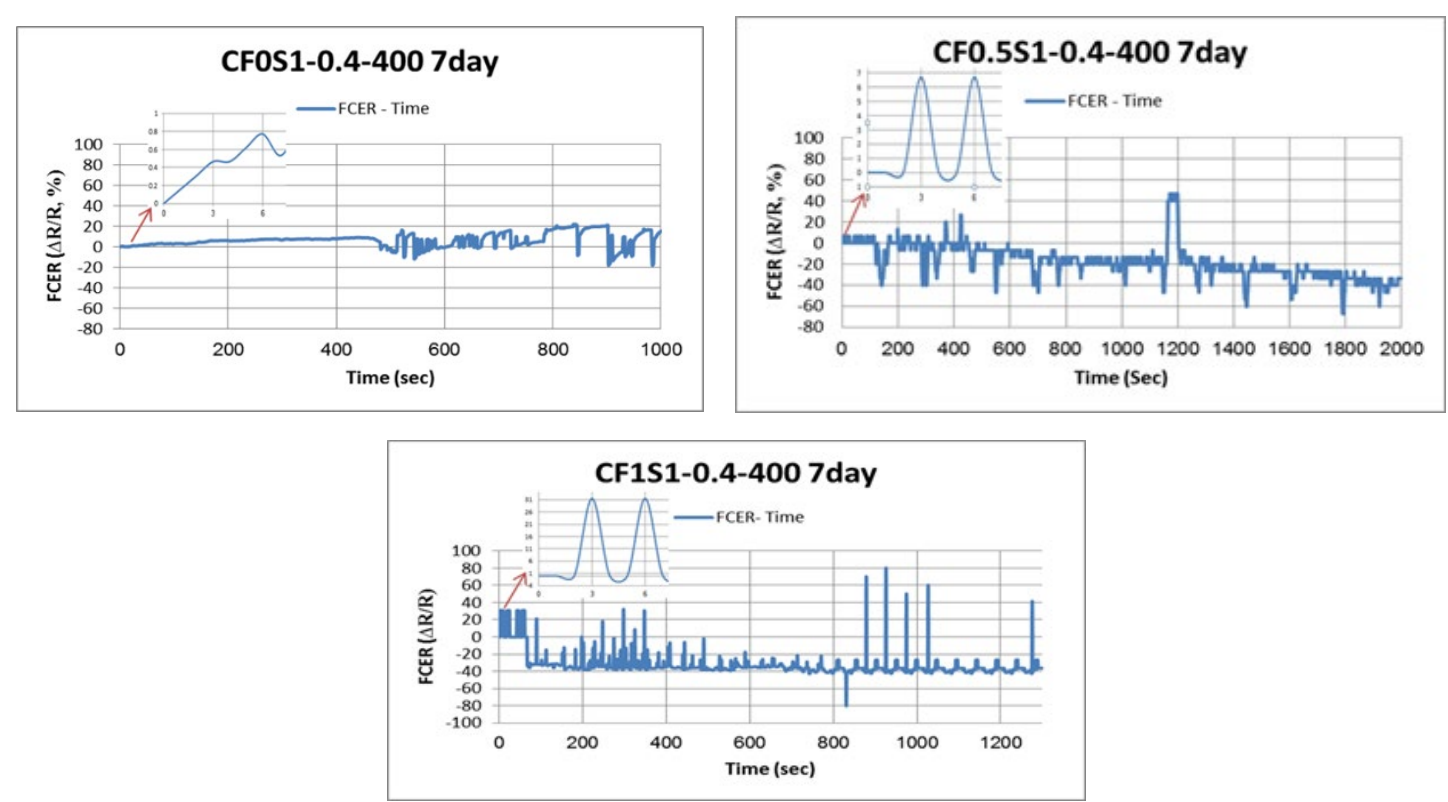

Figure 8: Effect of carbon fibers utilization on the average FCER results under impact load for different mixtures

Table 4: $\quad$ Impact Strength properties of FRCP

\begin{tabular}{lll}
\hline Impact Energy (KJ) & & \\
\hline FRCP mix & $7^{\text {th }}$ day & $28^{\text {th }}$ day \\
CF0S0 & 4.5 & 5.1 \\
FC0.5S0 & 4.99 & 5.5 \\
CF0S1 & 19.05 & 24.588 \\
CF0.5S1 & 49.99 & 63.504 \\
CF1S1 & 34.556 & 41.675 \\
\hline
\end{tabular}




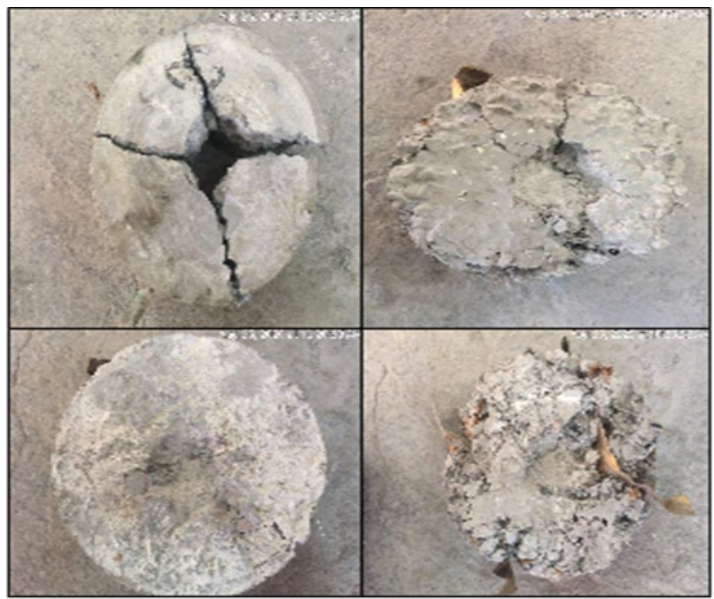

Figure 9: Failure of disc specimens under impact load

\section{Conclusions}

This study examined the comparative impact energy behaviors among macro-end hook steel fiber, microscale carbon fiber, and hybrid fiber of FRCPs under impact load. This involved the use of $1 \%$ by volume of mixture macro end hook steel fiber (S) (with lengths of 30 and $50 \mathrm{~mm}$ ) in FRCPS1 and, in other FRCP mixes, the use of $0.5 \%$ by volume micro-scale carbon fiber with length $12 \mathrm{~mm}$ (CF12) FRCPCF1 and addition of 0.5 and $1.0 \%$ vol. CF to FRCPS1 mixtures. The effect of CF content was also investigated concerning the self-sensing capabilities of FRCP under impact load. Two CF volume fractions $(0.5 \%$ and $1.0 \%)$ were investigated in this way. The following conclusions can be drawn based on the results:

1) The results showed an increase in impact energy with an increase in the content of fibers in the concrete.

2) The CF0S1mixture showed enhanced impact energy followed by CF0.5S0, while the superior impact energy was gotten with the mixture CF0.5S1.

3) The addition of $0.5 \%$ CF by volume improved the impact energy of the FRCP better than other percentages.

4) Improved self-sensing capability was achieved by increasing the CF content, with higher self-sensing capacity obtained at $1.0 \%$ vol., which also enhanced reversibility upon unloading at the elastic range.

Author contribution All authors contributed equally to this work.

Funding

This research received no specific grant from any funding agency in the public, commercial, or not-for-profit sectors.

Data availability statement

The data that support the findings of this study are available on request from the corresponding author.

\section{Conflicts of interes}

The authors declare that there is no conflict of interest.

\section{References}

[1] M. Nili and V. J. I. j. o. i. e. Afroughsabet, Combined effect of silica fume and steel fibers on the impact resistance and mechanical properties of concrete, Int. J. Impact. Eng., 37 (2010) 879-886. https://doi.org/10.1016/j.ijimpeng.2010.03.004

[2] H. Alabduljabbar, R. Alyousef, F. Alrshoudi, A. Alaskar, A. Fathi, and A. J. F. Mustafa Mohamed, Mechanical effect of steel fiber on the cement replacement materials of self-compacting concrete,Fibers, 7 (2019)36. https://doi.org/10.3390/fib7040036

[3] V. Ramkumar, G. Murali, N. P. Asrani, and K. J. J. o. B. E. Karthikeyan, Development of a novel low carbon cementitious two stage layered fibrous concrete with superior impact strength, J. Build. Eng., 25 (2019)100841. https://doi.org/10.1016/j.jobe.2019.100841

[4] V. Gopalaratnam and S. P. Shah, Properties of steel fiber reinforced concrete subjected to impact loading, in Journal Proceedings, 83 (1989) 117-126.

[5] ACI Committee 544: ACI PRC-544.2-17: Report on the Measurement of Fresh State Properties and Fiber Dispersion of Fiber-Reinforced Concrete, ACI, USA, Report 2017.

[6] B. Han and J. Ou, Embedded piezoresistive cement-based stress/strain sensor, Sens. Actuators., A138 (2007) 294-298. https://doi.org/10.1016/j.sna.2007.05.011 
[7] L. Vertuccio, L. Guadagno, G. Spinelli, P. Lamberti, V. Tucci, and S. J. C. P. B. E. Russo, Piezoresistive properties of resin reinforced with carbon nanotubes for health-monitoring of aircraft primary structures, J. Civ. Struct. Health Monit., 107 (2016)192-202. https://doi.org/10.1016/j.compositesb.2016.09.061

[8] D. D. J. M. S. Chung and E. R. Reports, Self-monitoring structural materials, MSEB., 22 (1998) 57-78. https://doi.org/10.1016/S0927-796X(97)00021-1

[9] A. Al-Dahawi, O. Öztürk, F. Emami, G. Yıldırım, and M. Şahmaran, Effect of mixing methods on the electrical properties of cementitious composites incorporating different carbon-based materials, Constr Build Mater., 104 (2016) 160-168. https://doi.org/10.1016/j.conbuildmat.2015.12.072

[10] A. Al-Dahawi et al., Electrical percolation threshold of cementitious composites possessing self-sensing functionality incorporating different carbon-based materials, SMS,. 25 (2016) 1-15.https://doi.org/10.1088/0964-1726/25/10/105005

[11] A. M. Al-Dahawi, Effect of curing age on the self-sensing behavior of carbon-based engineered cementitious composites (ECC) under monotonic flexural loading scenario, MATEC Web of Conferences, 162, 2018.

[12] G. Yıldırım, M. H. Sarwary, A. Al-Dahawi, O. Öztürk, Ö. Anıl, and M. Şahmaran, Piezoresistive behavior of CF- and CNT-based reinforced concrete beams subjected to static flexural loading: Shear failure investigation, Constr. Build. Mater., 168 (2016) 266-279. https://doi.org/10.1016/j.conbuildmat.2018.02.124

[13] M. H. Sarwary et al., Self-Sensing of Flexural Damage in Large-Scale Steel-Reinforced Mortar Beams, ACI Mater. J., 116 (2019) 209-221. http://dx.doi.org/10.14359/51715581

[14] F. Mussa, A. Al-Dahawi, Q. S. Banyhussan, M. R. Baanoon, and M. A. Shalash, Carbon Fiber-Reinforced Asphalt Concrete: An Investigation of Some Electrical and Mechanical Properties, IOP Conference Series: MSEB., 737 (2020) 012122. http://dx.doi.org/10.1088/1757-899x/737/1/012122

[15] G. Yıldırım, O. Öztürk, A. Al-Dahawi, A. A. Ulu, and M. Şahmaran, Self-sensing capability of Engineered Cementitious Composites: Effects of aging and loading conditions, Constr. Build. Mater., 231 (2020)117-132. https://doi.org/10.1016/j.conbuildmat.2019.117132

[16] D. Chung, Electrically conductive cement-based materials, Adv. Cem. Res. ,16(2004)167-176. https://doi.org/10.1680/adcr.16.4.167.46658

[17] P. Xie, P. Gu, and J. J. Beaudoin, Electrical percolation phenomena in cement composites containing conductive fibres, J. Mater. Sci., 30 (1996) 4093-4097. https://doi.org/10.1007/BF00352673

[18] S. Wen and D. Chung, Cement-based controlled electrical resistivity materials, J. Electron. Mater., 30 (2001)1448-1451. https://doi.org/10.1007/s11664-001-0200-2

[19] B. Han, X. Yu, and J. Ou, Self-sensing concrete in smart structures. Butterworth Heinemann-Elsevier, pages cm,2014

[20] H.-y. Chu, J.-k. J. C. Chen, and C. Composites, The experimental study on the correlation of resistivity and damage for conductive concrete, Cem. Concr. Compos., 67 (2016) 12-19. https://doi.org/10.1016/j.cemconcomp.2015.12.005

[21] S. Rana, P. Subramani, R. Fangueiro, and A. G. J. A. M. S. Correia, A review on smart self-sensing composite materials for civil engineering applications, AIMS Mater. Sci., 3 (2016) 357-379. https://doi.org/10.3934/matersci.2016.2.357

[22] A. Al-Dahawi, G. Yıldırım, O. Öztürk, and M. Şahmaran, Assessment of self-sensing capability of Engineered Cementitious Composites within the elastic and plastic ranges of cyclic flexural loading, Constr. Build. Mater., 145 (2017) 1-10. https://doi.org/10.1016/j.conbuildmat.2017.03.236

[23] D.-J. Kwon, Z.-J. Wang, J.-Y. Choi, P.-S. Shin, K. L. DeVries, and J.-M. J. C. P. B. E. Park, Damage sensing and fracture detection of CNT paste using electrical resistance measurements, Compos. B. Eng., 90 (2016) $386-391$. https://doi.org/10.1016/j.compositesb.2016.01.020

[24] A. Bouhamed, A. Al-Hamry, C. Müller, S. Choura, and O. J. C. P. B. E. Kanoun, Assessing the electrical behaviour of MWCNTs/epoxy nanocomposite for strain sensing, Compos. B. Eng., $128 \quad$ (2017) https://doi.org/10.1016/j.compositesb.2017.07.005

[25] G. Georgousis et al., Strain and damage monitoring in SBR nanocomposites under cyclic loading, Compos. B. Eng., 131 (2017) 50-61. https://doi.org/10.1016/j.compositesb.2017.08.006

[26] J. Wang, W. Wang, C. Zhang, and W. J. C. P. B. E. Yu, The electro-mechanical behavior of conductive filler reinforced polymer composite undergone large deformation: A combined numerical-analytical study, Compos. B. Eng., 133 (2018)185-192. https://doi.org/10.1016/j.compositesb.2017.09.041

[27] S. Wen, D. J. C. Chung, and C. Research, Uniaxial tension in carbon fiber reinforced cement, sensed by electrical resistivity measurement in longitudinal and transverse directions, Cem. Concr. Res., 30(2000)1289-1294. https://doi.org/10.1016/S0008-8846(00)00304-5 
[28] S. Wen, D. J. C. Chung, Uniaxial compression in carbon fiber-reinforced cement, sensed by electrical resistivity measurement in longitudinal and transverse directions, Cem. Concr. Res., 31(2001)297-301. https://doi.org/10.1016/S0008-8846(00)00438-5

[29] S. Wen and D. Chung, Self-sensing of flexural damage and strain in carbon fiber reinforced cement and effect of embedded steel reinforcing bars, Carbon, 44(2006)1496-1502. https://doi.org/10.1016/j.carbon.2005.12.009

[30] S. Wen and D. Chung, Electrical-resistance-based damage self-sensing in carbon fiber reinforced cement, Carbon, 45 (2007)710-716. https://doi.org/10.1016/j.carbon.2006.11.029

[31] D. G. Meehan, S. Wang, and D. Chung, Electrical-resistance-based sensing of impact damage in carbon fiber reinforced cement-based materials, J. Intell. Mater. Syst. Struct., 21(2010)83-105. https://doi.org/10.1177/1045389x09354786

[32] D. L. Nguyen, J. Song, C. Manathamsombat, and D. J. J. C. P. B. E. Kim, Comparative electromechanical damagesensing behaviors of six strain-hardening steel fiber-reinforced cementitious composites under direct tension, Composites, Part B, 69(2015)159-168. https://doi.org/10.1016/j.compositesb.2014.09.037

[33] J. Song, D. L. Nguyen, C. Manathamsombat, and D. J. J. J. o. C. M. Kim, Effect of fiber volume content on electromechanical behavior of strain-hardening steel-fiber-reinforced cementitious composites, J. Compos. Mater., 49(2015)3621-3634. https://doi.org/10.1177/0021998314568169

[34] Q. Mao, B. Zhao, D. Sheng, and Z. L. J. J. o. W. U. o. T.-M. Science, Resistance changement of compression sensible cement speciment under different stresses, Journal of Wuhan University of Technology-Materials Science,1996.

[35] M. K. Kim, D. J. Kim, and Y.-K. J. C. P. B. E. An, Electro-mechanical self-sensing response of ultra-high-performance fiber-reinforced concrete in tension, Compos. B. Eng., 134(2018)254-264. https://doi.org/10.1016/j.compositesb.2017.09.061

[36] N. Banthia, S. Djeridane, M. J. C. Pigeon, and C. research, Electrical resistivity of carbon and steel micro-fiber reinforced cements, Cem. Concr. Res., 22(1992)804-814. https://doi.org/10.1016/0008-8846(92)90104-4

[37] S. Wen and D. Chung, A comparative study of steel-and carbon-fibre cement as piezoresistive strain sensors, Adv. Cem. Res., 15(2003)119-128. https://doi.org/10.1680/adcr.15.3.119.36621

[38] A. Naaman and H. Reinhardt, Characterization of high performance fiber reinforced cement composites-HPFRCC, in High performance fiber reinforced cement composites,2(1996) 1-24.

[39] D. joo Kim, S. El-Tawil, A. E. J. M. Naaman, Rate-dependent tensile behavior of high performance fiber reinforced cementitious composites, Compos. B. Eng., 42 ( 2009)399-414. https://doi.org/10.1617/s11527-008-9390-X

[40] D. L. Nguyen, D. J. Kim, G. S. Ryu, and K. T. J. C. P. B. E. Koh, Size effect on flexural behavior of ultra-highperformance hybrid fiber-reinforced concrete, Compos. B. Eng., 45(2013)1104-1116. https://doi.org/10.1016/j.compositesb.2012.07.012

[41] D. L. Nguyen, G. S. Ryu, K. T. Koh, and D. J. J. C. P. B. E. Kim, Size and geometry dependent tensile behavior of ultrahigh-performance fiber-reinforced concrete, Compos. B. Eng., 58,2014, $279-292$. https://doi.org/10.1016/j.compositesb.2013.10.072

[42] D.-L. Nguyen, D.-K. Thai, and D.-J. J. T. J. o. S. A. f. E. D. Kim, Direct tension-dependent flexural behavior of ultrahigh-performance fiber-reinforced concretes, J. Strain. Anal. Eng. Des., 52( 2017) 121-134. https://doi.org/10.1177/0309324716689625

[43] N. A. al-Bayati, N. A. J. E. Hadi, and T. Journal, Experimental Behavior of Hybrid Steel and Polypropylene Fiber Reinforced Concrete Deep Beam Containing Openings, Eng. Technol. J., 36(2018). https://doi.org/10.30684/etj.36.2A.7

[44] M. H. F. Rasheed, A. Z. S. J. E. Agha, and T. Journal, Computational Analysis of punching shear models of steel fiber reinforced concrete slabs, Eng. Technol. J., 38(2020)126-142. https://doi.org/ 10.30684/etj.v38i2a.39

[45] Iraqi specification 5: Portland cement, 1984.

[46] Standard specification for coal fly ash and raw or calcined natural pozzolan for use in concrete, 2005.

[47] Standard Specification for Silica Fume Used in Cementitious Mixtures, 2020.

[48] Iraq Specofications. 45: Aggregate sieve analysis, 1984.

[49] Q. S. Banyhussan, G. Yıldırım, E. Bayraktar, S. Demirhan, M. J. C. Şahmaran, and b. materials, Deflection-hardening hybrid fiber reinforced concrete: The effect of aggregate content, Struct. Concr., 125(2016)41-52. https://doi.org/10.1016/j.conbuildmat.2016.08.020

[50] Q. S. Banyhussan, G. Yıldırım, Ö. Anıl, R. T. Erdem, A. Ashour, and M. J. S. C. Şahmaran, Impact resistance of deflection-hardening fiber reinforced concretes with different mixture parameters, Struct. Concr., 20(2019)1036-1050. https://doi.org/10.1002/suco.201800233 
[51] S. Demirhan et al., Impact behaviour of nanomodified deflection-hardening fibre-reinforced concretes, Mag. Concr. Res., 72(2020) 865-887. https://doi.org/10.1680/jmacr.18.00541

[52] H. Li, J. Ou, H. Xiao, X. Guan, and B. Han, Nanomaterials-enabled multifunctional concrete and structures, in Nanotechnology in civil infrastructure : A paradigm shift, K. Gopalakrishnan, B. Birgisson, P. Taylor, and N. O. AttohOkine, Eds. Berlin, Heidelberg: Springer Berlin Heidelberg, (2011)131-173.

[53] M.-q. Sun, R. J. Liew, M.-H. Zhang, and W. Li, Development of cement-based strain sensor for health monitoring of ultra high strength concrete, Constr. Build. Mater., 65(2014)630-637.https://doi.org/10.1016/j.conbuildmat.2014.04.105

[54] G. J. E. Salman and T. Journal, Density and ultrasonic pulse velocity investigation of self-compacting carbon fiberreinforced concrete, Eng. Technol.j., 36(2018). https://doi.org/10.30684/etj.2018.136783

[55] A. A. Nia, M. Hedayatian, M. Nili, and V. A. J. I. J. o. I. E. Sabet, An experimental and numerical study on how steel and polypropylene fibers affect the impact resistance in fiber-reinforced concrete, Int. J. Impact Eng., 46(2012)62-73. https://doi.org/10.1016/j.ijimpeng.2012.01.009

[56] D.-L. Nguyen, D.-J. Kim, and D.-K. J. M. Thai, Enhancing damage-sensing capacity of strain-hardening macro-steel fiber-reinforced concrete by adding low amount of discrete carbons, J. Mater., 12(2019)938. https://doi.org/10.3390/ma12060938

[57] P.-W. Chen, X. Fu, and D. J. M. J. Chung, Microstructural and mechanical effects of latex, methylcellulose, and silica fume on carbon fiber reinforced cement, J. Mater., 94(1997) 147-155.

[58] Q. S. Banyhussan, A. N. Hanoon, A. Al-Dahawi, G. Y1ldırım, and A. A. Abdulhameed, Development of gravitational search algorithm model for predicting packing density of cementitious pastes, J. Build. Eng., 27(2020). https://doi.org/10.1016/j.jobe.2019.100946

[59] D. D. L. Chung, Piezoresistive cement-based materials for strain sensing, J. Intell. Mater. Syst Struct ., 13(2002)599-609. 